\title{
INTRODUCTION - FROM DENOUNCING GENDER INEQUITIES TO UNDOING GENDER IN EDUCATION: PRACTICES AND PROGRAMMES TOWARD CHANGE IN THE SOCIAL RELATIONS OF GENDER
}

\author{
NELLY P. STROMQUIST and GUSTAVO E. FISCHMAN
}

Gender is a term that has been widely used in linguistics to designate a noun as masculine, feminine or neuter, but since the 1950s it has been used by academicians and has been ascribed additional meanings. While psychologist Money (1955) was among the first to use "gender" to distinguish manliness and womanliness, it is the publication of Ann Oakley's essay "Sex, Gender and Society" in 1972 (see Oakley 1997) that signalled the moment that it became a core concept in feminist studies. Soon after, but not without difficulties and debate, "gender" began to be employed regularly among social scientists and in everyday conversations.

Since then, thousands of articles, books and conferences have been dedicated to analysing the relationship between gender and education, and yet it seems that, more than 60 years since Simone de Beauvoir proclaimed in the Second Sex (1973: 301) that "One is not born a woman, but becomes one", discussions and debates on the topic remain ambiguous and confusing. Gender is frequently used in place of "sex", or as an indication of an interest in "women's" issues, or of concerns with sexualities, femininities and masculinities. Among educational researchers and practitioners working in universities, international institutions and local school districts there appears to have developed a general practice of using "sex" to refer to biological distinctions between women and men, reserving "gender" for the cultural and social aspects of the biological category of "sex". However, even this seemingly simple and general distinction remains problematic for some researchers. ${ }^{1}$

Hence, in no way do we want to suggest that this recognition was an easy process that developed "naturally". On the contrary, the fact that there are still wide disagreements on the meaning and uses of the concept is a clear indication of the challenges and difficulties in addressing gender/sex differences. ${ }^{2}$ What we want to highlight here is that discourses about gender need to be understood within the scientific paradigms that framed them and, as such, are not detached from ideological conflicts and social relations, or developed in a historical vacuum. What is designated under the category of gender or what is considered a gender issue in education is not a straightforward reflection of the economic, social, political, cultural, racial and religious dynamics conditioning the educational experiences of men and women, 
but gender is constructed within these conditions. An example from the field of education and development illustrates our perspective.

During the mid-1970s feminist perspectives began to gain momentum and become more influential in the field of education and development. These perspectives centred on the economic and political conditions of women, and paid considerable attention to women's needs in such key areas as access to land, credit, education, training and employment. This emphasis, known as Women in Development (WID), was also sensitive to what were considered to be "women's viewpoints". WID was a step forward from previous development frameworks that ignored women, but it presented clear limitations, particularly because its advocates often assumed that the solution was simply a matter of including women in existing institutions and structures rather than of understanding the complexity of the relations between men and women.

By the 1980s, a decade later, a more sophisticated analytical framework, Gender and Development (GAD), was developed. GAD asserted that it was not merely women's conditions but rather the interactions between men and women that created processes that reproduced the asymmetrical social relations of gender in society. Those involved with GAD attempted to be more sensitive to power relations and acknowledged that gender differences led to inequalities of power between women and men as well as among women. ${ }^{3}$ Nevertheless, GAD, too, was criticised for exposing narrow "Western" feminist perspectives and failing to pay attention to the interactions between gender, race and class. ${ }^{4}$

In addition to these concerns, activists and scholars from Africa, Asia and Latin America also pointed out that in many parts of the world the use of "gender" implied a form of minimisation and depolitisation of women's rights (Kolawole 2004) that ignored urgent problems and obscured feminist claims, making the demands of women less intimidating to the masculine and patriarchal majority leadership of international aid and development agencies and governments (Lazreg 2005; Staudt 2002).

Recognising the contributions as well as the limitations of past scholarship provides the basis for this special IRE issue on undoing gender in education. After years of efforts aimed at comprehending the functioning and consequences of discrimination based on sexual and gender distinctions and asymmetries, it has become imperative that we move into a proactive mode that shifts from the identification of conditions and problems to sustained attempts to push forward improvements and find solutions. Thus, the spirit of this special issue is to identify and explore successful forms of shaping new gender regimes and to understand how they come into being and what consequences they may generate. ${ }^{5}$ In this collection of articles, we seek to shift from a language of denunciation to one that, without losing its critical perspective, also recognises changes, and challenges, and contributes to the creation of new realities. The task is both conceptual and pragmatic: how can gendered representations and ideas be modified in the direction of 
diminishing inequalities between and within multiple masculinities and femininities? How can we undo the effects of external and internalised oppression? How can we move into practices that weaken discriminatory gender constructions and their practices?

\section{Understanding gender}

Most debates about gender have three general unifying or salient characteristics. First, these debates occur mostly among feminists and to a lesser, but significant, extent among critical scholars. Second, in these debates there is a tendency to conceptualise gender in relational and binary terms; i.e. masculinity is constructed in contrast to femininity and forms of masculinities/femininities in relation to other forms of masculinities and femininities. This tendency is often expressed as opposing ways of masculinity and femininity, with the former oppressing the later. Third, and following the notion of gender as a relational phenomenon, a key concern among feminist intellectual and activist circles has been to identify the mechanisms that reproduce gender in societies and find ways of intervening in those relationships of production and reproduction. ${ }^{6}$

As we noted above, the relationship between gender and sex is highly contested. In part, the lack of consensus in this area relates to and replicates the traditional debates between nature and nurture in the social sciences. Our point of departure is that, biologically speaking, females and males are similar in most ways. Gayle Rubin's classic perspective clarifies this:

From the standpoint of nature, men and women are closer to each other than either is to anything else - for instance, mountains, kangaroos, or coconut palms... the idea that men and women are two mutually exclusive categories must arise out of something other that a non-existent "natural opposition" (1975: 178).

Males and females are distinguishable only by a small, although very important, range of differences ultimately manifest in the selective reproductive capacity of the female body. ${ }^{7}$ But while biology and physiology are not irrelevant in the multifaceted processes of becoming a man, a woman, transsexual or transgender, differences at the chromosomic, hormonal and morphological levels become a beacon (Giddens 1993), a signalling system of organising expectations and interaction rather than the fixed cause of differentiation between those identities.

We are not disputing the likelihood that the biological influences are responsible for some behavioural differences, but that they cannot completely account for gender distinctions and sexual differences. In this regard, Judith Butler's concept of performativity is helpful to overcome the limitations of other conceptual perspectives relying on externally imposed and internalised fixed identities. She states that "the gendered body [as] performative suggests 
that it has no ontological status apart from the various acts which constitute its reality" (Butler 1993: 136). The advantages of using Butler's performative concept of gender is that a sense of identity (including sexual, ethnic and class identity) is bound to a dynamic set of non-essential practices that uncovers the way to alternative performances, even in the most restrictive spaces. ${ }^{8}$ In other words, there are more than two "gender possibilities produced within the repressive and constraining practices of our compulsory heterosexist culture" (Schrift 1995: 96).

As a socio-historical dynamic that affects and is affected by individual and social practices, some of them consciously and others unconsciously exercised, gender is always in the process of being done, performed and acted, and is thus present in the relationships between individuals of the same or different sexes, between individuals and society, and between individuals and institutionalised structures of power. As Judith Butler explains:

If gender is a kind of a doing, an incessant activity performed, in part, without one's knowing and without one's willing, it is not for that reason automatic or mechanical. On the contrary it is a practice of improvisation within a scene of constraint. Moreover, one does not "do" gender alone. One is always "doing" [it] with or for another, even if the other is imaginary (2004: 1).

Our understanding is that the constant "doing" of gender (West and Zimmerman 1987) and the notion of "undoing it" (Butler 2004; Deutsch 2007) and the identification of its multiple manifestations and widespread presence, should not be understood as an analytical proposal that searches for a simple and definite social marker, but as a complex phenomenon that underlies many individual and social conflicts, even though it is not activated in every one of those situations. Similarly, even if the presence of gender does not mean that it will be the central focus of every individual and social conflict, it should not be discarded beforehand as an irrelevant characteristic. On the contrary, understanding the intersectionality of gender - the way gender combines with other deep attributes such as ethnicity, race, religion and social class to create disadvantages and advantages on some occasions requires a careful examination of gendered patterns and their possible connections (or lack of them) with related struggles and conflicts.

The use of gender from an intersectional perspective permits the analysis of women's and men's experiences, not as isolated categories but as part of broader social relationships in which women are commonly positioned as a subordinate group in the allocation of resources and responsibilities. There is an important distinction between acknowledging differences and accepting the social rules ascribed to a given form, on the one hand, and embodying these forms by conforming to the hegemonic form of being a "man" or a "woman" in a given society, on the other. International, national, regional, ethnic and, especially, class variations are of enormous importance in mediating sexual differences and producing different patterns of gender relations. While gender is a major social marker that produces clear disadvantages for 
women (as national statistics regarding access to education, work, pay, political office and credit demonstrate), we want to reaffirm is that all women and men are not affected in the same way by historical circumstances because:

There is no "women" and no "woman's experience." Masculine and feminine are always categories within every class, race, and culture in the sense that women's and men's experiences, desires, and interests differ within every class, race, and culture. But so, too, are class, race, and culture always categories within gender, since women's experiences, desires, and interests differ within every class, race, and culture (Harding 1987: 7).

Kabeer, Harding and other feminist scholars have convincingly suggested that experiences do not have essential meanings outside a particular discursive context. This point is captured by Joan Scott's reflection that "Experience is at once always already an interpretation and is in need of interpretation. What counts as experience is neither self-evident nor straightforward; it is always contested, always therefore political" (1992: 36). Understanding gender regimes as discourses of power and identity implies the challenge of exploring the connections between what is experienced and how those experiences are represented.

Deutsch (2007) remarks that there is a certain reluctance to change, often expressed as resistance by both the oppressor and the oppressed. The former will be reluctant to relinquish the current favourable status, wealth and prestige. The latter will be hesitant to move into unknown or conflictive arenas. This tension between inevitability and reluctance implies that nothing remains completely static in society. Deutsch is also correct in observing that change does not come easily and some changes are much more contested than others. For those concerned with the large field of education and its political implications, consideration of organisations is critical in the analysis of gender. Politics are not institution-free (March and Olsen 1989); they are embedded in particular organisations and institutions, and in order to change oppressive structures we have to know how they are created and maintained by and within institutions. In fact, political institutions define the framework within which politics takes place.

The developments of the concept of gender and gender perspectives have represented not only theoretical improvements but also greatly influenced public policies. Nevertheless, there is a common tendency to treat gender as synonymous with women's topics, and that is a shortcoming. There are historical and political reasons behind this tendency. Attempts to preserve patriarchal and unequal sexual and cultural relationships, or the "invisibility" of women, in most of the social sciences studies for several decades have been the catalyst for a strong reaction, mainly among feminist theorists and practitioners, that has rightly placed "women first". Yet, stressing the role and experiences of women, though required to advance gender equity, is by itself an insufficient theoretical and political strategy. In other words, if the 
emphasis is understood as focusing solely on women, then it can be interpreted that the problem, and hence the solution to it, rests entirely with women, alienating the possibilities of creating meaningful alliances with groups of men.

Now, if we are concerned with propitiating fairness and equity in gender terms, it is evident we need to modify social structures and norms because structural change does not happen "naturally". Although natural events (such as earthquakes) can precipitate social changes, the modifications we discuss here can only be driven by "agents", i.e. social actors operating within specific yet continually evolving sets of constraints and opportunities. These can both restrict what actors can achieve and also enable them to exploit opportunities and events to design the new spaces necessary to bring about wider changes (Cerny 2000).

To sum up this section on the use of the concept of gender, we would like to point out that (a) gender practices, discourses, beliefs and institutions do not exist detached from power relations or in an historical vacuum; (b) what is designated under the category of gender or what is considered a gender issue is not a straightforward reflection of the social, racial, religious, ethnic and economic conditions of men and women; instead, gender is constructed within these conditions; and (c) understanding the intersectionality of gender dynamics is crucial to detecting moments in which the creation of new social attitudes and practices may be fostered.

\section{Understanding agency}

Again we emphasise that gender issues in educational settings should not be understood and addressed as if they were organised in a unified and progressive story that pays attention first to girls, then to boys, and later to transsexuals, ignoring the relational interdependencies of gender dynamics (Weaver-Hightower 2003). In other words, there is no "natural progression" from pre-feminist perspectives that ignore gender differences to a postfeminist queer perspective asking for the dismissal of the term (Bornstein 1994). In a similar way, the complex and difficult processes needed to achieve equality, mainstream gender and end gender discrimination cannot be reduced to a single story that will be "solved" by a homogenous and privileged organic agent of change. That is, gender dynamics always involve multiple narratives and subjects, engaged in overlapping and constantly shifting conflicts over recognition, representation and redistribution (Fraser 2008).

Agency is needed both for resistance (refusing to act in conventional ways) and for transgression (acting in new ways and toward new realities). The agency needed for change touches two different but complementary levels: the individual and the collective. In addition, working with agency implies accepting and functioning within an intersubjective dimension that 
pays attention to the ways that rules, norms and symbols are utilised on an everyday basis (Guzzini 2000), and carefully examining the social environment to recognise practices that reinforce gender as well as those that create contradictions.

While we recognise the importance of agency, we also consider that a sense of collective identity is instrumental to the success of collective actors. Shared experiences of subordination can contribute to the shaping of a collective identity, but past oppression is not a guarantee of future empowerment. The experience of injustice and discrimination needs to be accompanied by the development of a critical understanding of the experience. Both the experience and the understanding are crucial, yet not sufficient to a successful transformation of discriminatory rules, for, as Freire (1998) came to recognise, a deep understanding of the complex processes of oppression and domination is not enough to guarantee personal or collective praxis. What must serve as the genesis of such an understanding is a recognition of the existence of multiple forms of oppression and that every individual participates in them. In other words, the commitment to the struggle against injustice is not "organic", nor is it more natural for some people than for others, yet it is a required step towards purposeful change. Melucci shares this view, and he underlines the importance of collective action in terms of solidarity, collective identity, consciousness and ideology; these levels for him are as important as those that bring action to the level of political mobilisation.

Agency comes from a sense of empowerment, which functions as a strong resource in giving both hope and confidence in combating gender discrimination and disadvantage. Change will bring moments of disorder and fear; thus, feelings of self-confidence are essential. ${ }^{9}$ Clearly, the types and degrees of gender empowerment that can be created vary depending on the age of the subject as a function of both her maturation and the experiences she has undergone to date. ${ }^{10}$ The promises and possibility of empowerment highlight the key positions that the school experience occupies as a space of hope and as an agency that can help create personalities that are less dichotomous in terms of masculinity and femininity and more democratic, demanding equal rights for all.

\section{Undoing gender, agency, universality and difference}

Because agents are socially located and embedded in particular group identities and social networks with different gender-embodied traditions, practices and perceived interests, the most important challenge to address is the tension between the tendency to maintain differences that symbolically define the group while at the same time abolishing differences in the name of equality. The constant tension between universalism and particularity is quite relevant and pervasive in gender terms, and open to the question of when 
difference and diversity must be defended and when universalist positions must be demanded.

Answering this question, while paying attention to the difference/equality axis, is perhaps the greatest challenge to undoing gender because at the heart of our notion of a feminist political project is that of self-sovereignty; that is, seeing the individual as having autonomy over himself or herself even while living in pre-existing social structures that constrain the potential of individual autonomy. Granted, to achieve this sense of autonomy implies a number of drastic changes in the way societies are currently structured and normalised. Change in gender relations requires difficult transformations in men and in women. Simple and complex reasons are at work, and moving away from traditional gender constructions implies a terrain fraught with uncertainty, discomfort and even fear. Conventional ways of acting and thinking about gender are deeply engrained in our psyche and in very ancient social structures.

While there is no doubting the enormous weight and odds against social equity, especially because they cannot be obtained without redistributive policies and the parallel process of recognising and accepting differences, the struggles to undo oppressive gender regimes based on a sense of human dignity are also ancient and deeply rooted. The social interactions that reduce gender differences, i.e. the language, practices, policies and structures that contribute to undoing gender (Deutsch 2007: 122), should be oriented by the pursuit of "the right to be equal when difference makes us inferior, and the right to be different when equality denies our specificity" (Sousa Santos n.d.).

Undoing gender demands that we address in each specific location the tension between the pursuit of equality and the respect of difference, and these understandings very likely imply moving to unfamiliar terrains, requiring the expansion of the levels of agency and clarity in the language used. There is a complex intersection between ideology, attitudes and practices (Sullivan 2004). This implies that social actors must be extremely conscious of how these forces support each other, and make transformations in our experience of gender a process of constant contestation, with advances and steps backwards. If gender consciousness is needed for the undoing of gender, effective forms to foster it must be built on knowledge. Feminism has been the most likely intellectual movement to provide the elements for gender consciousness, and thus for undoing gender. Initial steps will have to take place at the level of ideology and discourse: questioning taken-for-granted assumptions and challenging labels that frame gender issues in particular ways detrimental to a new vision. This process of learning should promote the development of self-awareness and reflexivity (Sullivan 2004).

A recent example of the much-discussed gender gap in mathematical skills illustrates not only the levels of challenges we face but also the types of analysis that are needed: 
Three years after the [then] president of Harvard, Lawrence H. Summers, got into trouble for questioning women's "intrinsic aptitude" for science and engineering and 16 years after the talking Barbie doll proclaimed that "math class is tough" a study paid for by the National Science Foundation has found that girls perform as well as boys on standardized math tests. Although boys in high school performed better than girls in math 20 years ago, the researchers found that is no longer the case. The reason, they said, is simple: Girls used to take fewer advanced math courses than boys, but now they are taking just as many" (Lewin 2008).

A clear explanation, perhaps, but a simple reason? Undoing the mathematics gap was anything but a simple process. It was certainly not a natural development, an inevitable progression, a magic trick, but the result of conscious intentions and actions of subjects and social actors. The undoing of this particular "gap" has been the result of multiple and hard-won struggles over decades, not only in the public and political arenas, but also in innumerable small, everyday interactions. We may recall the endless debates and negotiations, mostly in universities and schools, but also in the media, in homes; but it is important to acknowledge that this undoing was also resisted (perhaps in less conscious ways) in countless jokes and casual conversations.

We want to emphasise that the undoing of oppressive structures was never a simple matter of waiting for the "right type of agent" to be in place. For example, women educators and scientists were key actors in the undoing of the gender gap in math, but not the exclusive agent of change. To reform social structures requires the conscious effort of subjects with a sense of agency; yet, as subjects, we live in a world of structures that precedes us and, as such, we must be subjected to those structures before we are ever to become subjects "for ourselves".

\section{Undoing gender and education}

The example above - undoing the mathematics gender gap - is related to an empirical question of significance: what has happened in the past 50 years, during which time gender has been recognised as an educational issue? The recent report of the monitoring team of the Education for All initiative presents ample evidence of substantive improvements as well as the persistence of gender inequalities:

The goal of eliminating gender disparities in both primary and secondary education by 2005 was missed in a great majority of countries. Only 59 countries, about one-third of the 181 countries for which data are available, had achieved the gender parity goal, very few of them since 1999. Gender disparities persist in many countries, particularly at the upper levels: while $63 \%$ of countries with data had managed to eliminate gender disparities in primary education, only $37 \%$ had done so at the secondary level. Many countries with relatively high primary enrolment ratios need still to address equity issues (UNESCO 2007a: 47). 
The EFA report offers very strong data underscoring the progress made as well as the enormous challenges faced in achieving gender equity. ${ }^{11}$ One important development that has taken place in the last 50 years is that schools and other educational settings are recognised as key institutions in the manifold process of preserving social practices, and play a critical role in presenting and maintaining normative forms of sexuality and gender identity (Blount 2007). To act within schools requires first and foremost recognising them as sites where gender is produced, in order subsequently to use those sites for alternative purposes or to create new sites where old practices may be abandoned. Yet, avoidance of deep gender issues is a persistent practice among state institutions, including schools. Frequently, when the state expresses concern for gender issues in education, it sees the problem as one of equal access to education for both girls and boys, and of questions of women's underrepresentation within certain fields of study.

In many parts of the world, there have been improvements in curriculum issues since the 1980s, especially in content presented in textbooks. There is greater representation of women in significant historical positions, more illustrations on women in non-conventional roles, and a more inclusive use of language that recognises the existence of women as social protagonists and subjects. However, much more remains to be done, especially in the linking of gender to broader issues such as diversity and social inclusion, and to controversial topics such as sexuality and interventions in the area of the teaching profession. ${ }^{12}$

There is an extensive body of research indicating that educational institutions offer important opportunities to explore the diversity of gender images and roles, among both educators and students. For these two groups, there is a clear need for exploring and understanding models of parenthood in which the sharing of tasks and practices regarding care-giving, household work and economic provision takes place. The roles of teachers and administrators need to be reconceptualised, away from the masculine traditions that dominate state-run schools (Lugg 2007). Training for teachers and administrators should help them become much more cognizant of the school culture, making them aware of its various actors and their interactions (Bank 2007). Training should also enable teachers and administrators to develop the ability to identify and effectively respond to conflict, misunderstanding and miscommunication regarding gender issues. Further, these educational actors need to acquire the knowledge and skills to deal with particular situations, instead of avoiding or ignoring them.

Youngsters should also learn about the importance of balancing outside work and domestic life, so that, as adults, job responsibilities will not exempt household and family concerns. Explicit sex education will be critical and this should go beyond issues of anatomy and physiology, as well as STDs and contraception, to explore aspects of desire, sexuality, sexual harassment and sexual identity. Sexual power relations are an implicit and pervasive part of the everyday schooling experience (Bank 2007). 
The messages emphasise heterosexuality, which creates the concomitant fear of and antagonism towards homophobia. Often, homophobic feelings are developed by failing to correct harassment practices that were "normalised" and even ritualised in youth peer culture; in the absence of sanctions against sexual and sexual-orientation harassment, such practice becomes naturalised.

Since sexual harassment is an everyday practice in which notions of masculinity and femininity are created, training students, teachers and administrators to address sexual harassment has been shown by research to make a difference in increasing both awareness and the likelihood that victims will seek help (Paludi 2007). Extracurricular activities, such as engagement in student government, sports and mathematics clubs, tend to enhance feelings of self-worth, thereby creating school spaces that foster as well as protect new ways of doing gender. Change in the social relations of gender calls for daily contestation and struggle.

In this respect, Sullivan (2004) identifies two kinds of struggle: the "underground approach" (retraining, coaching and praising) and "direct confrontational techniques". Obviously, both are needed to encourage recognition of the existence of multiple models of masculinity and femininity for girls and boys. Peer cultures, especially in industrialised countries, promote and enforce dominant notions of masculinity and femininity, especially in middle and high school. This implies frequent use of social insults and aggressive approaches to others - usually girls, or boys who do not perform their masculinity according to patriarchal rules. These age groups correspond with periods of intensive physical and psychological change, which makes the victims very vulnerable (Bank 2007). Peer cultures, particularly among students from low socio-economic sectors, tend not to relate to academic concerns and are much more interested in social relations with their peers, making submission and lack of resistance of others much more likely.

The importance of peer cultures and the relative success of educational innovations outside the formal school system have produced important instances of change and lessons in the processes of doing/undoing gender over the last 50 years. Non-formal education programmes, which are often less monitored by the state and its institutions, have helped create spaces for new gender conceptions and practices. As the articles contributing to this special issue illustrate, programmes effective in "undoing gender" have been implemented in various parts of the world. ${ }^{13}$

\section{This special issue}

"Undoing gender" is founded on the premise that societies are not static, that they change over time. Since gender is a social construction, it is amenable to change but, as a deeply embedded social variable, gender also tends to resist modification. The fact that gender varies in importance depending on particular historical, lifecycle-related, cultural and economic situations, 
obliges us to pay attention to issues of intersectionality. This special issue explores several approaches with a demonstrated ability to undo gender or at least to possess significant potential to achieve new and more positive configurations of gender.

The articles that constitute this special issue explicitly face the need to engage in action to remove or at least erode the structures and practices that confirm and strengthen gender on an everyday basis. Undoing gender implies a sequential journey that moves from pronunciation (e.g. "I am a woman") to denunciation (e.g. "I am marginalised as a woman because of social and cultural forces"), and thence to activation (i.e. "I must act to correct the undesirable situation"). On the other hand, the articles in this special issue represent relatively modest examples of undoing gender. Why? Education takes time to develop and mature. The chain of effects that derive from learning, educational experiences and the acquisition of knowledge will materialise at different times and at different ages.

Two articles in this special issue describe interventions at the secondary school level in settings that serve low-income students and show evidence on the basis of comparison with control groups. The article by Monisha Bajaj examines structures and processes in a Zambian private institution which, in an effort to diminish gender influences, has set up single-sex programmes for its students. While this measure has been deplored in other countries as creating settings that produce gendered differences in school offerings, in the Zambian case the existence of girls-only classes is found to generate opportunities for leadership and self-confidence. The curriculum deals explicitly with values such as peace, equity and social justice, and the daily assemblies provide space for self-expression. At the same time, school practices that involve all students - girls and boys - in maintenance and community service tasks usually relegated to women foster an active degendering of such activities and, consequently, of everyday life.

Erin Murphy-Graham depicts a more comprehensive and encompassing effort in Honduras - the SAT programme - that has been implemented outside the public school system. Through the creation of its own instructional materials, deployment of study groups, use of tutors and provision of services to the surrounding community, the students involved in this programme - many of them women - learn to question the gender system and to act otherwise, particularly in areas involving the division of domestic labour, domestic violence and leadership. This study highlights the importance of deliberate planning in the components of an intervention designed to empower women and thus to break down engrained gender stereotypes and practices. A curriculum linked to social justice values and the training of tutors to facilitate critical reflection on gender issues and hegemonic masculinity emerge as two powerful components of this innovative approach.

The article by Sherrie Carinci and Pia Wong probes gender knowledge and attitudes in a rather unusual way. By comparing responses of men and women across different generations and levels of education in the USA, they 
draw inferences regarding changes in the perception of gender effects upon society. Their article is not on undoing gender but rather on assessing how gender, under different conditions, might have been undone (or not) in recent years. By submitting the study participants to three scenarios, the researchers collect data regarding their understanding of how gender functions. Their findings give occasion for pause. While women detect more gender implications than men, older women seem to demonstrate a greater awareness than younger women. In particular, younger generations are found to have a weaker grasp of historical events and legal details, which leads Carinci and Wong to conclude that changes in values and attitudes may not be sufficient to undo gender in the absence of knowledge.

Also focusing on adult women and men, the article by Golnar Mehran takes a sobering look at higher education in Iran through the use of gender parity indicators. Applying the Women's Empowerment Framework proposed by Sara Longwe, she examines a hierarchy of empowering conditions. Under the present Islamic Republic in Iran, a number of contradictory dynamics are at work. As in many other parts of the world, there has been a notable expansion in access to higher education, with women moving to near equality at the bachelor's level. However, the more socially and economically rewarding degrees, those at the master's and doctorate levels, continue to register a minority representation of women. Islamic ideologies about proper "feminine" and "masculine" occupations are guiding selection of fields of study, which show considerable gender polarisation, with women having greater representation in all fields of study but remaining a minority in engineering fields. Nonetheless, women obtain a smaller proportion of the advanced degrees and are underrepresented as senior faculty in the university. Mehran finds that, in contrast with Longwe's model, it is possible for women to gain participation in the public sphere before having reached a consciousness of their unequal status elsewhere. State and religious institutions are potent mechanisms that resist "undoing gender". Nonetheless, despite the limited opportunities for social and political action, gender relations are undergoing change in Iran. Mehran's contribution resides in highlighting the explicit contradictions in Islamic education policies, which are simultaneously empowering and disempowering, and produce unintended imbalances between men and women in higher education.

Barbara Cole proposes to use the concept of intersectionality in conjunction with narrative as a theoretical and methodological toolbox to explore ways of "undoing gender". In her article, Cole examines the use of narratives in depicting social events and interactions and how narrative methodologies can help us detect moments of resistance/transgression. From a feminist standpoint integrated with tools of critical discourse analysis and dialogical qualitative perspectives, Cole acknowledges that "narratives" are not a panacea and can, in fact, contribute to increasing the marginalisation of populations positioned as "other" in a given context. Nevertheless, as Cole concludes, "we cannot choose silence" (Pillay 2007: ix), confirming the 
relevance of presenting social phenomena in great detail and complexity through narrative. This perspective, described as "telling it as it is for them, in their context, and in their time, in all the complexity, diversity, incompleteness and inequality" serves to develop deeper understanding of the doing and undoing of gender regimes, and the importance of incorporating comprehensive research methodologies when planning and implementing public policies and programmes.

The article by Sondra Cuban proposes the notion that post-structural pedagogies can offer a new baseline with great potential for the multi-layered project of undoing gender. In the context of a workplace course of English for Speakers of Other Languages (ESOL), Cuban provides a nuanced analysis of the challenges involved in undoing gender with migrant populations in England. This research project analysed how adult students and teachers created a community of practice in which, in precarious and strategic ways, they found solidarity, subverting a gendered ESOL curriculum established by employers with a focus on etiquette and diction and more concerned with the reproduction of hierarchical relations of dependence than with providing a sound and professionally relevant curriculum. Using the metaphor of "tightrope walking" (Fenwick 2007), Cuban describes how - through a more participatory model of learning that is not anticipated in the formal curriculum developed for this group - adult immigrants working as care-givers for the elderly, along with their teacher, explore differences in the technical and emotional problems involved in their jobs. Through those explorations, executed in a careful and balanced manner, the group found not only validation for all their emotional, intellectual and physical labour, but also alternative ways to improve their care-giving professional skills.

As Greg Knotts notes in his contribution, legal actions have often been used to promote social change, particularly in the USA and in the state of California, but enforcing harassment policies, though clearly relevant, is not enough to undo oppressive gender regimes. Knotts explores both the public and private manifestations of two legislative initiatives: AB 394 (the Safe Place to Learn Act), and $A B 537$ (protecting children from gender related harassment in schools). Using data from a qualitative study that explored how administrators and teachers in public schools in California understood and used specific legal instruments addressing gender and sexual orientation, this study makes evident that the existence of "a law" preventing discrimination in schools (its public face) needs to be complemented by dialogues and curricular actions aimed at the creation of contexts of accepting difference, challenging heteronormativity and discriminatory gender regimes, preventing harassment and producing more comprehensive understandings of gender and sexuality. Knotts concludes his study with a series of guidelines and suggestions for schools that complement the spirit of the legal measures as one part of a larger strategy for social and cultural change.

The article by Samuel Davidson brings together the narratives of three "gender bending" male adolescents of colour gathered in the course of a 
four-year Practitioner Research project. Davidson created a narrative attempting to remain as faithful as possible to participants' experiences of the overlapping of gender performances, whereby gender-bending and gender-quiet males address the thorny themes of sexuality, ethnicity, spirituality and culture. In Davidson's work, the use of the term "gender-quiet" does not imply that the participants were shy or timid; on the contrary, it is a demonstration of their "agency". The participants used gender silence to expand their territories, thereby opening borderlands in which they were safe to explore and express their feminine masculinities. Davidson concludes that it is in these borderlands that these three young men silently exercise their commitment to redefining, reclaiming and redirecting their masculinities by hybridising them and incorporating feminine perspectives.

In all, we believe that this collection of articles breaks new ground in the conceptualisation of change in the social relations of gender. Its scope, incorporating both formal education and informal learning, is wide. It brings issues of sexuality to the fore, an element usually excluded from educational discussions. Furthermore, it comprises efforts by a whole array of agents, from the individual to the collective, from the state to non-governmental organisations, and from school-level changes to those on a larger, even national, scale.

\section{Acknowledgments}

Each of the articles in this special issue benefited from the critique and advice of two peer reviewers. We wish to express our deep thanks to the various women and men in various institutions of higher education from different parts of the world who provided us with their comments. We also wish to thank Assistant Editor, Hannah Mowat, our constant contact at IRE, for her prompt and most thoughtful performance.

\section{Notes}

1. Although we believe that the distinction between "gender" and "sex" is widely accepted, it is important to recognise that for some researchers it merits more discussion. For example, a recent article in Educational Researcher concludes: "The practice of using the term gender to refer to a vague, ill-defined aspect of men's and women's experience or as a synonym for sex is widespread in everyday and academic writing. Indeed, gender has largely eclipsed sex (often implicitly defined as a binary biological category) as the preferred term for naming differential aspects of male and female experience, thinking, and practice. This situation is infrequently noted and - when it is noted - is rarely seen as a problem" (Glasser and John Smith 2008: 349).

2. In this regard it seems that Sylvia Walby's (1997) well-known categorization of the social sciences with regard to gender are relevant today: gender can be ignored or reduced to a negligible attribute; gender becomes part of the criticism of the previous disregard; "women" becomes a general category and is incorporated as a 
"special case" to compensate the former neglect; and, finally, full conceptual integration of gender becomes a central concept in the analytical approach.

3. The differences between WID and GAD are also connected to the different developmental and historical contexts. During that period, feminism in industrialised countries tended to differ considerably from those in developing countries: the former focused on gender identity and, to some extent, ethnicity, and the latter on the intersection with social class and issues of national development, such as the satisfaction of basic needs and human rights.

4. Kabeer (1994: 65) noted that "While 'gender is never absent', it is never present in pure form. It is always interwoven with other social inequalities, such as class and race, and has to be analyzed through a holistic framework if the concrete conditions of life for different groups of women and men are to be understood".

5. A gender regime is "a structure of gender relations" that "does not mechanically determine how people or groups act. That is the error of social determinism, and it is no more defensible than biological determinism. But a structure of relations certainly defines possibilities and consequences for action" (Connell 2009: 74).

6. These three characteristics are linked to the tendency shared by most feminists and critical theorists to focus on historical and contextual analysis as well as on normative questions about what a "good society" should be. One of the most significant political projects aims at creating a new form of citizenship, one that not only increases women's participation in decision-making and paid labour, but also redraws the borderlines of what is often referred to as the public and private spheres, and changes the material and symbolic conditions to which men and women relate. This political project also aims at recasting the notions of masculinity and femininity, making it possible for wider forms of sexuality and sexual orientation to be expressed and performed. Depending on the historical and political contexts, many of these objectives are, of course, heavily contested.

7. Connell, in his classic book Gender and Power (1987), also pointed to the key position of reproductive capabilities in gender regimes, and argued that gender is a linking concept between fields of social practice and the nodal practices of childbirth and parenting.

8. "Transactional sex" represents another important area of contention at the crossroads of sex, gender, race, cultural and religious practices that highlights the importance of contextualising our analysis. Sarah Humphreys and her colleagues clearly illustrate this point: "While the genderedness of poverty is not in dispute and evidence abounds on the need for poor young girls in Africa to have sex to meet basic needs, this image of sexual exploitation tends to overshadow the multiplicity of meanings that these interactions might hold for participants in different contexts (Undie and Benaya 2006). One of the problems is that underlying a lot of this research, much of which has been carried out by non-African researchers, is an implied Western morality that romantic love and/or personal pleasure are the 'proper' motives for engaging in sex, while strategic, materially oriented reasons are not, as they are most notably embodied in the Western image of the prostitute" (Humphreys et al. 2008: 24).

9. Oliver and Marwell (1992) write about two action technologies, which might also be considered as two important dimensions of empowerment. In their view, people who fight against oppression need production technologies (i.e. bodies of knowledge about ways of achieving goals such as lobbying, demonstrations, strikes or attending public hearings) and mobilization technologies (i.e. ways of accumulating resources such as the time and money necessary for production technologies).

10. Outside the school experience, women must gain tools to renegotiate their private lives, particularly to deal with gender asymmetries with their spouses. For most 
women, it is also difficult to cast off previous practices and beliefs because many draw confidence and identity from the established division of labour that places women in direct contact with and responsibility for household management and childcare. Especially among older women, transitions into new roles and modified identities produces anxiety and the certainty of losing whatever levels of social protection they now have. Change is not exclusively a difficult process for women. For most men, it is often extremely difficult to surrender economic and social benefits that have traditionally generated power and prestige for them. Whether in the household or at work, having women "in their place" means less competition with men and more resources for men to use.

11. Among the most important challenges, the EFA report concludes, "sexual violence, insecure school environments and inadequate sanitation disproportionately affect girls' self-esteem, participation and retention. Textbooks, curricula and teacher attitudes continue to reinforce stereotypes on gender roles in society" (EFA 2007b: 3).

12. The need persists, even in countries where notable progress has been made regarding these issues. An examination of selected mandated curriculum guidelines for grades 1-10 in three Canadian provinces, for instance, found that discourse on multiculturalism emphasises harmony while marginalising conflict and critical viewpoints; it also presents injustices as either past or resolved problems. The social science curriculum "mentioned abstract concepts of social justice and bias, but usually not attached to particular instances, causes or ramifications" (Bickmore 2006: 371).

13. In the Latin American region, instances of educational programmes that have been quite successful in "undoing gender" can be found in Colombia, Mexico and Brazil. In Colombia, a programme that allowed women to complete secondary school has enabled them to become kindergarten teachers and work for the benefit of their community while earning a salary. In Mexico, a programme in favour of peace and against violence reaches both students in public schools and their educational personnel and parents. In Brazil, a programme led by an AfroBrazilian NGO in collaboration with the Ministry of Education and Culture addresses the intersection between sexism and racism in the public education system, from school to university. In all three cases, the interventions aim at increasing the participants' self-esteem, as well as their awareness of gender relations and agency.

\section{References}

Bank, Barbara. 2007. Peer Cultures and Friendships in School. In: Gender and Education. An Encyclopedia, ed. by Barbara Bank, 605-611. Westport, CT: Praeger.

Bickmore, Kathy. 2006. Democratic Social Cohesion (Assimilation)? Representations of Social Conflict in Canadian Public School Curriculum. Canadian Journal of Education 29(2): 359-386.

Blount, Jackie. 2007. Some Historical Tensions about Sexuality and Gender in Schools. In: Keeping the Promise. Essays on Leadership, Democracy, and Education, ed. by Dennis Carlson and C. P. Gause, 61-78. New York: Peter Lang.

Bornstein, Kate. 1994. Gender Outlaw. New York: Vintage Books.

Butler, Judith. 1993. Bodies that Matter: On the Discursive Limits of "Sex". New York: Routledge. 
Butler, Judith. 2004. Undoing Gender. New York: Routledge.

Cerny, Philip. 2000. Structuring the Political Arena. In: Global Political Economy. Contemporary Theories, ed. by Ronan Palan, 21-35. London: Routledge.

Connell, Robert. W. 1987. Gender and Power. Cambridge: Polity Press.

Connell, Raewyn. 2009. Gender., 2nd ed., Cambridge: Polity Press.

de Beauvoir, Simone. 1973. The Second Sex. New York: Vintage Books.

Deutsch, Francine. 2007. Undoing Gender. Gender and Society 21(1): 106-127.

Fenwick, Tara. 2007. Tightrope Walkers and Solidarity Sisters: Critical Workplace Educators in the Garment Industry. International Journal of Lifelong Education 26: 315-328.

Fraser, Nancy. 2008. Abnormal Justice. Critical Inquiry 34(3): 393-422.

Freire, Paulo. 1998. Teachers as Cultural Workers: Letters to Those Who Dare Teach. Boulder: Westview Press.

Giddens, Anthony. 1993. Sociology, 2nd ed., Cambridge: Polity Press.

Glasser, Howard M., and John III Smith. 2008. On the Vague Meaning of "Gender" in Education Research: The Problem, Its Sources, and Recommendations for Practice. Educational Researcher 37(6): 343-350.

Guzzini, Stefano. 2000. The Use and Misuse of Power Analysis in International Theory. In: Global Political Economy. Contemporary Theories, ed. by Ronen Palan, 53-66. London: Routledge.

Harding, Sandra. 1987. Introduction: Is There a Feminist Method? In: Feminism and Methodology, ed. by Sandra Harding, 7-14. Bloomington: Indiana University Press.

Humphreys, Sara, Chi-Chi Undie, and Máiréad Dunne. 2008. Gender, Sexuality and Development: Key Issues. In: Education and Society in Subsaharan Africa, ed. by Sara Humphreys, 7-40. Rotterdam: Sense Publishers.

Kabeer, Nahila. 1994. Reversed Realities: Gender Hierarchies in Development Thought. London/New York: Verso.

Kolawole, Mary. 2004. Re-conceptualising African Gender Theory: Feminism, Womanism and the Arere Metaphor. In: Re-thinking Sexualities in Africa, ed. by Signe Arnfred. Uppsala: The Nordic Africa Institute.

Lazreg, Marnia. 2005. Decolonizing Feminism. In: African Gender Studies: A Reader, ed. by Oyeronke Oyĕwùmí. New York: Palgrave Macmillan.

Lewin, Tamar. 2008 (25 July). Math Scores Show No Gap for Girls, Study Finds. New York Times. Accessed online at http://www.nytimes.com/2008/07/25/education/ 25math.html.

Lugg, C. A. 2007. Sissies, Faggots, Lezzies, and Dykes: Gender, Sexual Orientation, and a New Politics of Education?. In: Keeping the Promise. Essays on Leadership, Democracy, and Education, ed. by Dennis Carlson and CP Gause, 117-158. New York: Peter Lang.

March, James, and Johan Olsen. 1989. Rediscovering Institutions. The Organizational Basis of Politics. New York: The Free Press.

Money, John. 1955. Hermaphroditism, Gender and Precocity in Hyper-adrenocorticism: Psychologic Findings. Bulletin of the Johns Hopkins Hospital 96: 253-254. 
Oakley, Ann. 1997. A Brief History of Gender. In: Who's Afraid of Feminism? Seeing through the Backlash, ed. by Ann Oakley and Juliet Mitchell. London: Hamish Hamilton.

Oliver, Pamela, and Gerald Marwell. 1992. Mobilizing Technologies for Collective Action. In: Frontiers in Social Movement Theory, ed. by Aldon Morris and Carol Mueller, 251-272. New Haven: Yale University Press.

Paludi, Michele. 2007. Sexual Harassment Policies and Practices. In: Gender and Education. An Encyclopedia, ed. by Barbara Bank, 793-800. Westport, Connecticut: Praeger.

Pillay, Venitha. 2007. Academic Mothers. Staffordshire, U.K: Trentham Books.

Rubin, Gayle. 1975. The Traffic in Women: Notes on the "Political Economy" of Sex. In: Towards an Anthropology of Women, ed. by R. Reiter, 157-210. New York: Monthly Review Press.

Schrift, Alan D. 1995. Nietzsche's French Legacy: A Genealogy of Poststructuralism. New York: Routledge.

Scott, Joan. 1992. Experience. In: Feminists Theorize the Political, ed. by Judith Butler and Jean Scott, 22-40. New York, London: Routledge.

Staudt, Kathleen. 2002. Dismantling the Master's House with the Master's Tools: Gender Work in and with Powerful Bureaucracies. In: Feminist Post-development Thought: Rethinking Modernity, Postcolonialism and Representation, ed. by Kriemild Saunders. London: Zed Books.

Sullivan, Oriel. 2004. Changing Gender Practices within the Household. Gender and Society 18(2): 207-222.

Undie, Chi Chi, and Kabwe Benaya. 2006. The State of Knowledge on Sexuality in SubSaharan Africa: Synthesis of Literature. JENDA: Journal of Culture and African Women Studies 8. Accessed online at http://www.jendajournal.com/issue8/undie-benaya.html.

UNESCO. 2007. Education for All by 2015. Will We Make It? Paris: UNESCO.

UNESCO. 2007. Summary: Education for All by 2015. Will We Make It?. Paris: UNESCO.

Walby, Sylvia. 1997. Gender Transformation. London: Routledge.

Weaver-Hightower, Marcus. 2003. The "Boy Turn" in Research on Gender and Education. Review of Educational Research 73(4): 471-498.

West, Candace, and Don H. Zimmerman. 1987. Doing Gender. Gender and Society 1(2): $125-151$.

\section{The authors}

Nelly P. Stromquist is a professor of international education policy in the College of Education at the University of Maryland. Dr Stromquist specialises in issues related to international development education and gender from a critical sociology perspective. Her research interests focus on the dynamics between educational policies and practices, gender relations, social justice and societal change. More recently, she has been studying how the processes of globalisation are shaping structures and functions of education. Her most recent books are Feminist Organizations and Social Transformation in Latin 
America and (ed.) The Professoriate in the Age of Globalization. She is a former president of the Comparative and International Education Society and a 2005-2006 Fulbright New Century Scholar.

Contact address: College of Education, University of Maryland, College Park, MD 20742, USA. E-mail: stromqui@umd.edu.

Gustavo E. Fischman is associate professor in the Mary Lou Fulton College of Education at Arizona State University. His areas of specialisation are comparative education, gender studies in education and the use of image-based methodologies in educational research. He actively teaches and collaborates on research projects in Argentina, Brazil, Mexico, Spain and the USA. He is the editor of the Spanish and Portuguese sections of Education Review and Educational Policy Analysis Archives. Dr Fischman has published four books, numerous articles and book chapters on education in journals such as Educational Researcher, Comparative Education Review, Journal of Education Policy, Gender and Education, Revista de Educación, Cuadernos de Pedagogía and Educaçao \& Realidade, among others.

Contact address: Mary Lou Fulton College of Education, Arizona State University, Tempe, AZ 85287-0211, USA. E-mail: fischman@asu.edu. 